https://doi.org/10.15407/ujpe66.8.699

R. YAGOUB,${ }^{1}$ H. REKKAB DJABRI,${ }^{2}$ S. DAOUd,${ }^{3}$ N. BELOUFA,${ }^{2}$ M. BELARBI,${ }^{2}$

A. HAICHOUR, ${ }^{2}$ C. ZEGADI, ${ }^{2}$ S. LOUHIBI FASLA ${ }^{2}$

${ }^{1}$ Laboratory of Plasma Physics, Materials, Conductors, and Their Applications (LPPMCA)

(Oran, USTO El M'Naouer, 31000, Algeria; e-mail: rym-yagoubi@yahoo.fr)

2 Laboratory of Micro- and Nanophysics (LaMiN), National Polytechnic School of Oran (ENPO-MA,BP 1523,El M'Naouer, 31000,Oran, Algeria; e-mail: souad.fasla@enp-oran.dz)

${ }^{3}$ Laboratory of Materials and Electronic Systems, Faculty of Sciences and Technology, Mohamed El Bachir El Ibrahimi University of Bordj BouArreridj (Bordj BouArreridj, 34000, Algeria)

\title{
FIRST PRINCIPLES STUDY OF HIGH-PRESSURE PHASES OF ScN
}

\begin{abstract}
We report the results of first-principles total-energy calculations for structural properties of scandium nitride (ScN) semiconductor compound in NaCl-type (B1), CsCl-type (B2), zincblende-type (B3), wurtzite-type (B4), NiAs-type (B81), CaSi-type (Bc), $\beta$-Sn-type (A5), and CuAu-type (L10) structures. Calculations have been performed with the use of the all-electron full-potential linearized augmented plane wave FP-LAPW method based on density-functional theory (DFT) in the generalized gradient approximation (GGA) for the exchange correlation energy functional. We predict a new phase transition from the most stable cubic NaCl-type structure (B1) to the $\beta$-Sn-type one (A5) at 286.82 GPa with a direct band-gap energy of about $1.9^{75} \mathrm{eV}$. Our calculations show that ScN transforms from the orthorhombic CaSi-type structure (Bc) to A5 at $315 \mathrm{GPa}$. In agreement with earlier ab initio works, we find that B1 phase transforms to Bc, L10, and B2 structures at 256.27 GPa, 302.08 GPa, and 325.97 GPa, respectively. The electronic structure of $A 5$ phase shows that $S c N$ exhibits a direct band-gap at $X$ point, with $E_{g}$ of about $1.975 \mathrm{eV}$.
\end{abstract}

Ke ywords: FP-LAPW, scandium nitride, phase transition, GGA, electronic structure.

\section{Introduction}

Recently, III-V based scandium and yttrium materials have received more attention because of their remarkable properties especially the high hardness and high melting point [1]. Among these materials, binary compounds scandium nitride $(\mathrm{ScN})$ and yttrium nitride (YN) which are of considerable importance because of their high mechanical strength, structural phase stability, and wide optical band gap [2]. Such remarkable characteristics empower them as potential semiconducting materials in the electronic industry as buffer layers and diffusion barriers, electric contacts, etc. [2]. Ul Haq et al. [2]. have reported structural parameters, electronic band structures, and optical properties of bulk ScN, YN, and their alloys $\left(\mathrm{Sc}_{x} \mathrm{Y}_{1-x} \mathrm{~N}\right)$ using the full-potential (FP)

(C) R. YAGOUB, H. REKKAB DJABRI, S. DAOUD, N. BELOUFA, M. BELARBI, A. HAICHOUR, C. ZEGADI, S. LOUHIBI FASLA, 2021 linearized augmented plane wave (LAPW) plus local orbitals (lo) methods with both Perdew generalized gradient approximations (GGA), and the Tran-Blaha modified Becke-Johnson (mBJ) potential. They found that $\mathrm{Sc}_{x} \mathrm{Y}_{1-x} \mathrm{~N}$ alloys have interesting optical characteristics, which gives a hope to use these materials in optoelectronic applications. Scandium nitride is an important group IIInitride material; it is formed from nitrogen with the electron configuration $[\mathrm{He}] 2 \mathrm{~s}^{2} 22 \mathrm{p}^{3}$ and scandium with the electron configuration: $[\mathrm{Ar}] 4 \mathrm{~s}^{2} 3 \mathrm{~d}^{1} . \mathrm{ScN}$ material could lead to novel materials with device functionalities, and it can overcome some of the limitations of other III-V semiconducting compounds [3].

Various theoretical approaches [4] have been utilized to investigate several physical properties III-V based scandium compounds. Based on the first-principles full-potential linearized augmented plane wave (FPLAPW) approach, Maachou et al. [4] have stud- 
ied the ground-state parameters, structural phase transitions, and electronic properties of four III-V based scandium compounds ( $\mathrm{ScN}, \mathrm{ScP}, \mathrm{ScAs}$, and $\mathrm{ScSb}$ ). They found that all these binary compounds transform from the NaCl-type phase to CsCl-type structure at pressures of around 364.32, 245.61, 92.40, and $39.78 \mathrm{GPa}$ for bulk $\mathrm{ScN}, \mathrm{ScP}, \mathrm{ScAs}$, and $\mathrm{ScSb}$, respectively. They have mentioned also that their results agree well with the available experimental data and other theoretical values. The vibrational and thermal properties of bulk $\mathrm{YN}$ and $\mathrm{ScN}$ materials were studied in Ref. [5] using the quasiharmonic approximation calculations plus anharmonic effects. Their results on structural properties, phonon frequencies, dielectric constants, and effective charges of $\mathrm{ScN}$ compound were found also in a reasonable agreement with other theoretical results and experimental data.

Adhikari et al. [6] have studied the structural phase stability, elastic constants, and electronic properties of bulk TiN, $\mathrm{ScN}, \mathrm{YN}, \mathrm{Ti}_{1-x} \mathrm{Sc}_{x} \mathrm{~N}$, and $\mathrm{Ti}_{1-x} \mathrm{Y}_{x} \mathrm{~N}$ $(0 \leq x \leq 1)$ alloys using the Monte Carlo technique, first principles methods, and cluster expansion formalism. Based on the results obtained in their work, they suggest the $\mathrm{Ti}_{1-x} \mathrm{Sc}_{x} \mathrm{~N}$ alloys for the implementation in hard coating applications. The straininduced evolution of structural parameters and electronic properties of rare-earth nitrides $(\mathrm{ScN}, \mathrm{YN}$, $\mathrm{LuN}$, and LaN) were investigated using the density functional theory (DFT) and the modified BeckeJohnson approach [7]. Their results show indirect $(\Gamma-X)$ band gaps of about $0.9,1.2$, and $1.1 \mathrm{eV}$ for bulk $\mathrm{ScN}, \mathrm{YN}$, and $\mathrm{LuN}$, respectively; while a small direct $(X-X)$ band gap of around $0.6 \mathrm{eV}$ was predicted for LaN semiconducting material. The pressure-induced structural phase transition, electronic properties, and elastic constants of some rareearth nitrides ( $\mathrm{ScN}, \mathrm{YN}$ and $\mathrm{LaN})$ using the DFT method were investigated in Ref. [8]. Their results show that all these binary compounds transform from the $\mathrm{NaCl}$ to CsCl-type structure at pressures of around 158, 132, and 26.5 GPa for $\mathrm{ScN}, \mathrm{YN}$, and LaN, respectively.

The investigation of physical properties of the binary compounds under hydrostatic pressure has been an active topic of researches in condensed matter physics over the previous decades [9]. In our earlier work, we published the results on the electronic properties of cubic ScGaAs and ScGaN ternar- ies and superlattices [10]. The phase transition from the rocksalt to the zincblende structure was investigated, and the possibility of zincblende/zincblende $\mathrm{GaN} / \mathrm{Sc}_{x} \mathrm{Ga}_{1-x} \mathrm{~N}$ and $\mathrm{GaAs} / \mathrm{Sc}_{x} \mathrm{Ga}_{1-x}$ As superlattices was expected, and direct gaps were found to be possible in these systems, predicting them as good candidates for optoelectronic applications. The purpose of this work is to provide some additional information to the available data on the physical properties of ScN with state-of-the-art first-principles calculations. The latter are the basis of solid-state science and industrial applications, and their study is of importance to extend our knowledge on their specific behavior, when undergoing severe constraints of high-pressure or high temperature environments. We extend our work to observe the effect of hydrostatic pressure on the structural properties of $\mathrm{ScN}$ using the first-principles total energy calculations in the framework of the DFT. Eight different phases for ScN compound, including the NaCl-type (B1), CsCltype (B2), zincblende (B3), wurtzite (B4), NiAs-type (B81), CaSi-type (Bc), $\beta$-Sn-type (A5), and $\mathrm{CuAu-}$ type (L10) structures have been considered. The paper is organized as follows. The method is briefly commented in Section 2. Results are discussed in Section 3, and then conclusions are summarized in Section 4 .

\section{Theoretical Framework}

We have employed the first-principles full-potential linearized augmented plane wave (FP-LAPW) method [11] implemented in the WIEN2k code [12]. The exchange and correlation effects are described in the framework of the DFT [13] using generalized gradient approximation (GGA) [14] parametrized Ref. [15] for the exchange and correlation energy functional. It is known that the local density approximation (LDA) uses the exchange correlation density of the uniform electron gas of the same charge density at every point in the system regardless of the inhomogeneity of the real charge density. The GGA also uses the gradient of the charge density to correct for this deviation. Therefore, it is thought to be more accurate [16]. In the FPLAPW method, the interstitial regions do not represent a problem, since the relative Kohn-Sham wave functions are expressed in plane waves. In the interstitial regions, the wave functions are expanded in plane waves with $\mathrm{RMT}^{*} K_{\max }$ fixed to 7 (RMT is the small- 
Table 1. NPLW, number of plane waves used in the interstitial regions;

RMTS is in atomic units, and $K$-point represents the number of special $K$-points

in the irreducible BZ involved in the calculations for $\mathrm{ScN}$ material

\begin{tabular}{|l|c|c|c|c|c|c|c|c|}
\hline \multicolumn{1}{|c|}{ Structures } & $\mathrm{NaCl}(\mathrm{B})$ & $\mathrm{CsCl}(\mathrm{B} 2)$ & $\mathrm{ZB}(\mathrm{B} 3)$ & $\mathrm{WZ}(\mathrm{B} 4)$ & $\mathrm{NiAs}(\mathrm{B} 81)$ & $\mathrm{CaSi}(\mathrm{Bc})$ & $\mathrm{AuCu}(\mathrm{L} 10)$ & $\beta-\mathrm{Sn}(\mathrm{A} 5)$ \\
\hline$L_{\max }$ & 10 & 10 & 10 & 10 & 10 & 10 & 10 \\
$\mathrm{RMT}^{*} K_{\max }$ & 7 & 7 & 7 & 7 & 7 & 7 & 7 & 7 \\
Total NPLW & 166 & 157 & 369 & 1447 & 572 & 1391 & 763 \\
RMT (Sc) & 2.2460 & 2.4180 & 2.1200 & 1.7400 & 2.0000 & 2.0640 & 2.1000 \\
RMT (N) & 1.7430 & 1.8790 & 1.7300 & 1.5000 & 2.0000 & 1.6890 & 2.0000 \\
K-point & 47 & 35 & 47 & 76 & 63 & 150 & 75 \\
\hline
\end{tabular}

est atomic sphere radius in the unit cell, and $K_{\max }$ is the maximum modulus for the reciprocal lattice vector). To ensure the correctness of our calculations, we have taken $L_{\max }=10$. Notice that the RMTS of the same atomic species can vary with different phases, since the full potential is utilized, which ensures no dependence of calculations on the RMTS. The details of calculations are listed in Table 1.

\section{Results and Discussion}

\subsection{Equation of state parameters}

First, we have calculated the equilibrium lattice parameters within the FPLAPW methods in GGA frameworks using the habitual minimization procedure. We optimized the possible space groups to find the total energy per unit cell (E) and their volume $(V)$ at a given pressure $(P)$. The different obtained values of the total energies are presented as functions of the unit cell volume. The structural parameters, bulk modulus, and its first derivative were obtained by fitting the numerical data to Murnaghan's equation of states (EOS) [17]:

$E(V)=E\left(V_{0}\right)+\frac{B_{0} V}{B_{0}}\left[\frac{\left(V_{0} / V\right)^{B_{0}^{\prime}}}{B_{0}^{\prime}-1}+1\right]-\frac{B_{0} V_{0}}{B_{0}^{\prime}-1}$

Here, $E\left(V_{0}\right)$ is the DFT ground-state energy (corresponding to the equilibrium volume $\left.V_{0}\right), V$ is the $\partial B / \partial P$, at $P=0)$.

There are several models proposed to relate the pressure and the volume during the construction and the analysis of $P-V$ data under compression. In our present work, the changes of the volumes were obtained in terms of the pressure according to the fol- lowing equation [18]

$P(V)=\frac{B_{0}}{B^{\prime}}\left(\left(V_{0} / V\right)^{B_{0}^{\prime}}-1\right)$

Figure 1 presents the variation of the total energy as a function of the unit cell volume in different configurations of $\mathrm{ScN}$. The lowest energy minimum corresponding to the $\mathrm{NaCl}$-type phase was observed for $\mathrm{ScN}$ compound, while the total energies of other configurations (B2, B3, B4, B81, Bc, A5, and L10) are higher.

So, we have confirmed that the rock salt is the ground state configuration for $\mathrm{ScN}$, while the $\mathrm{Bc}, \mathrm{A} 5$, L10, and B2 structures can be formed under pressure. Our results of the equilibrium lattice constants $(a, c / a$, and $b / a)$, internal parameters $(u, v)$, modulus of rigidity, and the pressure derivative of the modulus of rigidity of $\mathrm{ScN}$ material in different configurations are summarized along other data from the literature in Table 2. We can observe that our values of different structural parameters in general agree well with the results obtained from other calculations

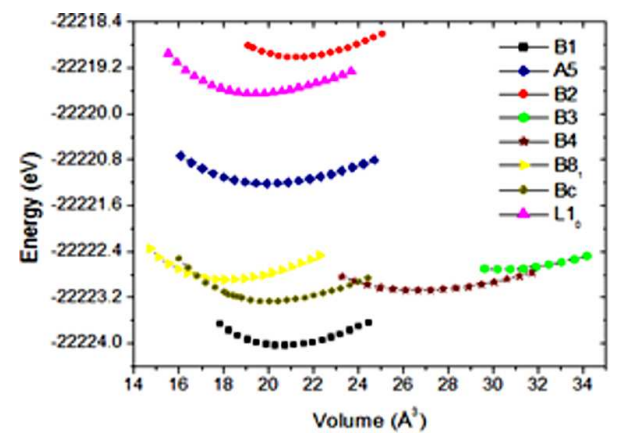

Fig. 1. Total energy versus volume for different configurations of $\mathrm{ScN}$ 
Table 2. Structural parameters (equilibrium lattice constants $a, c / a$, and $b / a$, and the internal parameters $u, v)$, bulk modulus $B_{0}$ and the pressure derivatives of the bulk modulus $B_{0}^{\prime}$ of eight configurations for $\mathrm{ScN}$ with other theoretical data from the literature

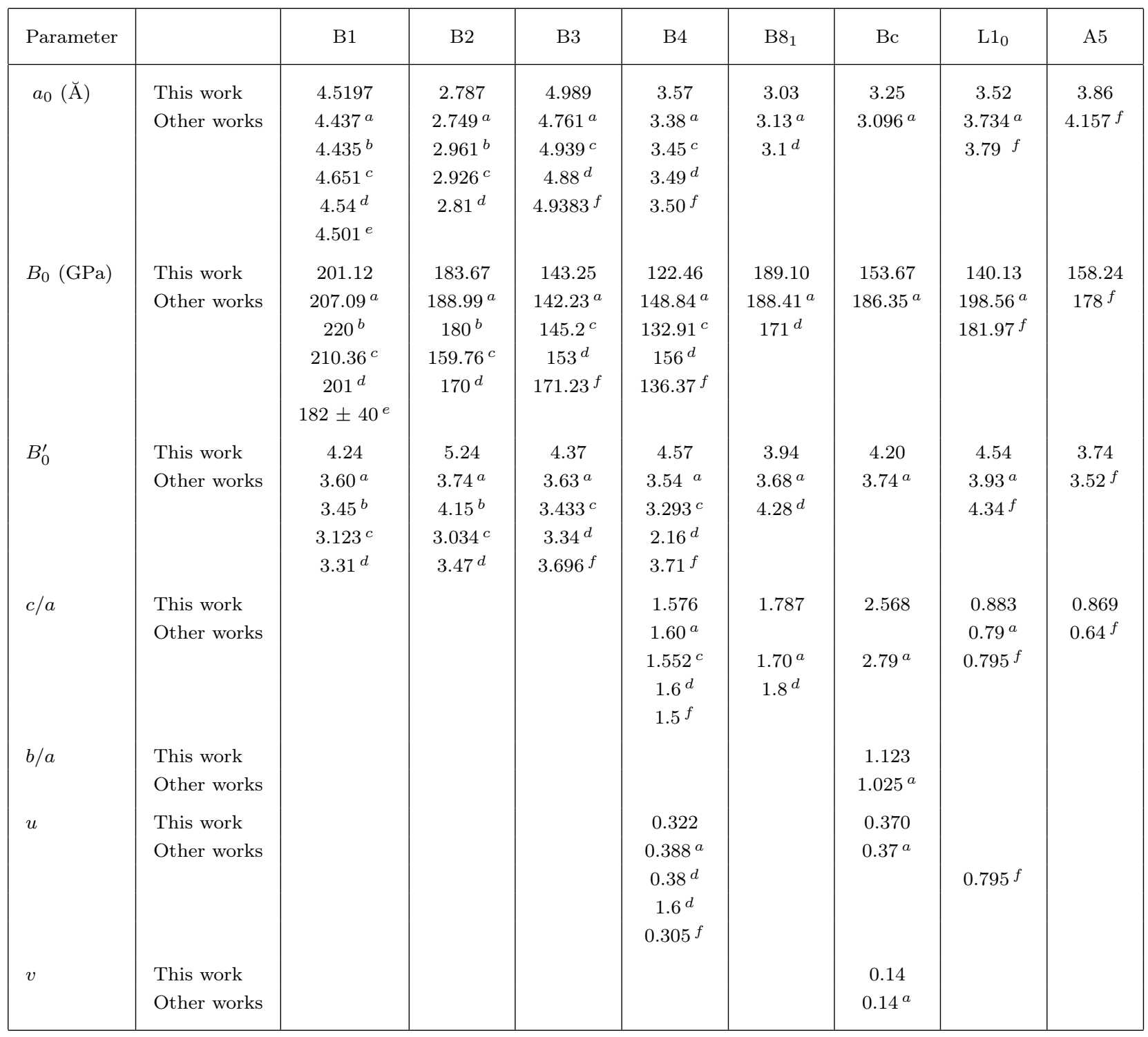

${ }^{a}$ Ref. [1], ${ }^{b}$ Ref. [8], ${ }^{c}$ Ref. [20], ${ }^{d}$ Ref. [21], ${ }^{e}$ Ref. [22], ${ }^{f}$ Ref. [19].

[19] and experimental investigations [22]. For example, our obtained value $(4.5197 \breve{\mathrm{A}})$ of the lattice constant $a_{0}$ for the cubic NaCl-type phase overestimates the experimental data $(4.501 \widetilde{\mathrm{A}})$ reported in Ref. [22] by less than $0.40 \%$, while our value $(2.7879 \breve{A})$ of $a_{0}$ for the cubic CsCl-type structure underestimates the theoretical value $(2.81 \breve{A})$ reported in Ref. [21] by around $0.79 \%$.
The bulk modulus (module of rigidity) describes the elastic properties of a solid, when all surfaces are under pressure (hydrostatic compression) [23]. It is an essential elastic parameter connected to the bonding strength of a solid, and it is used as a fundamental quantity for the calculation of material's hardness [24]. Moreover, the material with the highest bulk modulus has the lowest compressibility [25]. 
Our obtained values of the modulus of rigidity $B_{0}$ and its pressure derivative $B_{0}^{\prime}$ of different structures are also in general in agreement with other data reported previously in the literature [20]. For the B1 phase, the deviation between our obtained value $(201.12 \mathrm{GPa})$ of $B_{0}$ and the theoretical value $(201 \mathrm{GPa})$ reported in Ref. [21] is less than $0.06 \%$, while, for the B81 structure, our obtained value (3.94) of $B_{0}^{\prime}$ is localized between the two theoretical values 3.68 and 4.28 reported in Ref. [1] and in Ref. [21], respectively. For several materials of group-III-V, group-II-VI, and some other elements of group-IV, Adachi [26] showed the correlation between the elastic moduli and the melting temperature. For some binary semiconducting compounds of group-III-V, the correlation between the standard entropies $S^{0}(298 \mathrm{~K})$ and the melting points was observed [27].

For several materials with cubic structure, the melting point $T_{m}$ correlates with the bulk modulus $B$ by the following linear expression [28]

$T_{m}=604+9.3 B$,

where the bulk modulus $B$ is expressed in GPa, while the melting point $T_{m}$ is expressed in $\mathrm{K}$. Replacing our value $\left(B_{0}=201.12 \mathrm{GPa}\right)$ of the bulk modulus $B$ in Eq. (3), the melting point $T_{m}$ of the scandium nitride (B1-ScN) semiconducting material was found at around $2477.42 \mathrm{~K}$ which is slightly lower than the theoretical one Ref. [29] obtained from the elastic constant $\mathrm{C}_{11}$, but in very good agreement with the experimental ones 2550 and $2600 \pm 50 \mathrm{~K}$ reported in Ref. [30] and in Ref. [31], respectively. The deviation between our value $(2477.42 \mathrm{~K})$ of $T_{m}$ for the B1 phase and the experimental data $(2550 \mathrm{~K})$ reported in Ref. [30] is only around $2.85 \%$.

\subsection{Structural properties under high pressure}

The investigation of dielectrics, metallic materials, as well as semiconductors under high pressure has continued for several decades using powerful experimental techniques and more reliable computational approaches [32]. At elevated pressures, the crystal deforms and usually undergoes a structural phase transition. The latter is associated with a sudden change in the arrangement of the atoms, which are rearranged in new positions, which leads to a new structure [33]. Experimentally, the pressure of the phase

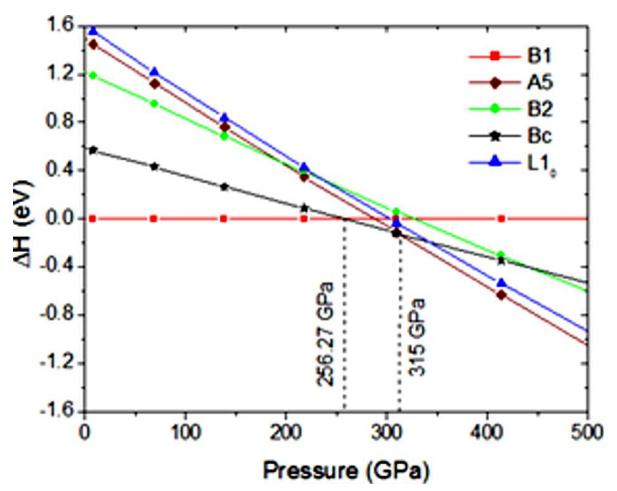

Fig. 2. Variation of the enthalpy differences as functions of the pressure for $\mathrm{Bc}, \mathrm{A} 5, \mathrm{~L} 10$, and B2

transition can be determined by investigating the lattice dynamics properties of our material of interest, using Raman scattering. At the transition point, the Raman scattering reveals a phase transition as the discontinuities in phonon frequencies or the intensity of phonon peaks [34]. For determining the most stable structure at any pressure and temperature, the free energies of different phases were usually used. The free energy $G$ of any particular phase is expressed as follows [35]:

$G=E+P V-T S$

where $E$ is the total energy, $P$ is the pressure, and $V$ is the volume, $T$ is the temperature, and $S$ is the entropy. Since our results are obtained at $T=0 \mathrm{~K}$, we have compared the enthalpies $H=E+P V$ per a formula unit of the material of interest in different phases. Our calculations show that the ground state configuration is the NaCl-type structure. Nevertheless, depending on the pressure, Bc, A5, L10, and B2 can be formed. Other structures have been considered in our calculations, but were not close to the stability in any interval of pressures of interest. In Fig. 2 for $\mathrm{ScN}$, we display the enthalpy differences for $\mathrm{Bc}, \mathrm{A} 5$, L10, and B2 as functions of the pressure with reference to the B1-type structure. The obtained results show that $\mathrm{ScN}$ undergoes a number of structural phase transitions under pressure. The new phase transition (B1 to A5) is predicted to occur at 286.82 GPa before the well-known phase transition (B1 to B2) at $325.97 \mathrm{GPa}$. It is clearly seen that our results confirm the presence of the orthorhombic $(\mathrm{Bc})$ structure at a pressure of around 256.27 $\mathrm{GPa}$ from the most stable phase cu- 
Table 3. Calculated values of the phase transition pressure $\boldsymbol{P}_{\boldsymbol{t}}$ (GPa) of ScN semiconducting compound and other theoretical literature data. $\mathrm{X}=(\mathrm{Bc}, \mathrm{A5}, \mathrm{L10}$, and B2)

\begin{tabular}{|c|c|c|c|c|c|}
\hline \multirow{2}{*}{ Parameter } & \multicolumn{5}{|c|}{ Transition } \\
\hline & & $\mathrm{B} 1 \rightarrow \mathrm{bc}$ & $\mathrm{B} 1 \rightarrow \mathrm{A} 5$ & $\mathrm{~B} 1 \rightarrow \mathrm{L} 1+0$ & $\mathrm{~B} 1 \rightarrow \mathrm{B} 2$ \\
\hline Pt (GPa) & $\begin{array}{l}\text { This work } \\
\text { Other works }\end{array}$ & $\begin{array}{l}256.27 \\
252.5^{a}\end{array}$ & $\begin{array}{c}286.82 \\
301.3^{h}\end{array}$ & $\begin{array}{c}302.08 \\
303.02^{a}, 1036^{h}\end{array}$ & $\begin{array}{c}325.97 \\
324^{a}, 364.32^{b}, 332.75^{c}, 341^{d}, \\
335^{e}, 368.46^{f}, 365.87^{g}, 412^{h}\end{array}$ \\
\hline$V_{\mathrm{B} 1(\mathrm{Pt})}\left(\breve{\mathrm{A}}^{3}\right)$ & $\begin{array}{l}\text { This work } \\
\text { Other works }\end{array}$ & $\begin{array}{c}14.90 \\
13.678^{a}\end{array}$ & 14.56 & $\begin{array}{c}14.38 \\
13.117^{a}\end{array}$ & $\begin{array}{c}14.19 \\
12.912^{a}, 13.5^{d}, 14.12^{e}\end{array}$ \\
\hline$V_{\mathrm{X}(\mathrm{Pt})}\left(\breve{\mathrm{A}}^{3}\right)$ & $\begin{array}{l}\text { This work } \\
\text { Other works }\end{array}$ & $\begin{array}{c}13.57 \\
13.101^{a}\end{array}$ & 12.49 & $\begin{array}{c}12.03 \\
12.535^{a}\end{array}$ & $\begin{array}{c}13.887 \\
12.149^{a}, 12.8^{d}, 13.68^{e}\end{array}$ \\
\hline$-\Delta / V_{\mathrm{B} 1(\mathrm{Pt})} \%$ & $\begin{array}{l}\text { This work } \\
\text { Other works }\end{array}$ & $\begin{array}{c}8.92 \\
4.218^{a}\end{array}$ & 14.25 & $\begin{array}{l}16.33 \\
4.44^{a}\end{array}$ & $\begin{array}{c}2.15 \\
5.9^{a}, 5^{d}, 3.9^{e}\end{array}$ \\
\hline
\end{tabular}

${ }^{a}$ Ref. [1], ${ }^{b}$ Ref. [4], ${ }^{c}$ Ref. [20], ${ }^{d}$ Ref. [21], ${ }^{e}$ Ref. [29], ${ }^{f}$ Ref. [36], ${ }^{g}$ Ref. [37],${ }^{h}$ Ref. [19].

bic B1, which is consistent with previous theoretical reports. On the other hand, we predict the phase transition from the orthorhombic phase $(\mathrm{Bc})$ to the $\beta$-Sn-type one (A5) at $315 \mathrm{GPa}$. Our result for the transition pressure from B1 to L10 is found at around $302.08 \mathrm{GPa}$ and agrees well with other calculated values in Ref. [1].

The transition pressures $(\mathrm{Pt})$ from $\mathrm{B} 1$ phase to other structures of $\mathrm{ScN}$ are summarized in Table 3 along other data of the literature [36], with the volume reduction for each transition. It can observe that our value of $P_{t}$ from $\mathrm{B} 1$ to $\mathrm{B} 2$ of $\mathrm{ScN}$ compound is in good agreement with other theoretical results [37]. Our obtained value $(325.97 \mathrm{GPa})$ of $P_{t}$ overes-

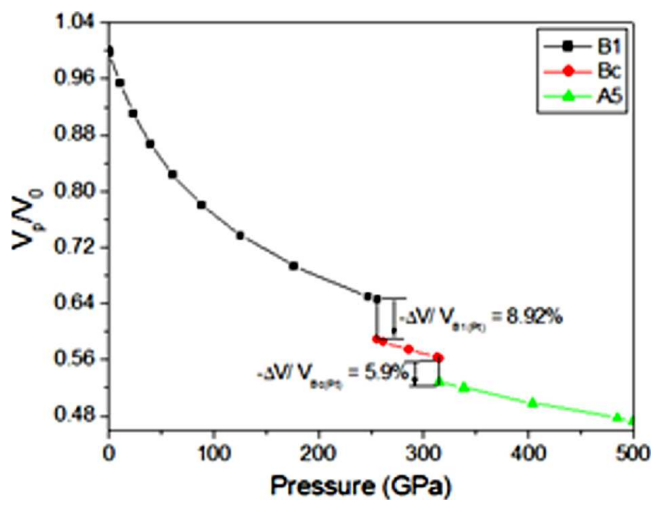

Fig. 3. $\left(V_{p} / V_{0}\right)$ versus pressure for the $(\mathrm{NaCl} \rightarrow \mathrm{CaSi} \rightarrow \beta$-Sn $)$ phases of ScN semiconducting compound timates the theoretical value $(324 \mathrm{GPa})$ reported in Ref. [1] by only around $0.61 \%$. To best of our knowledge, there are no experimental or theoretical data in the literature with the consideration of a constanttemperature limit to compare our results for the B1 to $\mathrm{A} 5$ and $\mathrm{BC}$ to $\mathrm{A} 5$ transitions for $\mathrm{ScN}$ material. According to Eq. (2), the variations of the curves (the volume versus the applied pressure $P-\left(V_{p} / V_{0}\right)$ for $\mathrm{ScN}$ ) for the $\mathrm{NaCl} \rightarrow \mathrm{CaSi}$, then from $\mathrm{CaSi} \rightarrow \beta$ $\mathrm{Sn}$ transitions are plotted in Fig. 3. From the previous curves, we can predict the volume collapses $\left.\left[-\left(V_{\mathrm{Bc}(\mathrm{Pt})}-V_{\mathrm{B} 1(\mathrm{Pt})}\right) / V_{\mathrm{B} 1(\mathrm{Pt})}\right)\right]=\left(-\Delta V / V_{\mathrm{B} 1(\mathrm{Pt})}\right)$, and $\left[-\left(V_{\mathrm{A} 5(\mathrm{Pt})}-V_{\mathrm{Bc}(\mathrm{Pt}))} / V_{\mathrm{Bc}(\mathrm{Pt})}\right]=\left(-\Delta V / V_{\mathrm{Bc}(\mathrm{Pt})}\right)\right.$ at the different points of the transition. It can be seen that there are about 8.92 and $5.9 \%$ volume reductions for the $\mathrm{B} 1 \rightarrow \mathrm{Bc}$, and $\mathrm{Bc} \rightarrow \mathrm{A} 5$ phase transitions, respectively. Our result $(256.27 \mathrm{GPa})$ for $P_{t}$ for the transition from $\mathrm{B} 1 \rightarrow \mathrm{Bc}$ is in excellent agreement with the value $(252.5 \mathrm{GPa})$ reported in Ref. [1], it is clear that our result $(8.92 \%)$ regarding the volume collapse during the transition from $\mathrm{B} 1 \rightarrow \mathrm{Bc}$ is very higher than the theoretical value $(4.218 \%)$ reported in Ref. [1].

In addition to $\mathrm{B} 1 \rightarrow \mathrm{Bc} \rightarrow \mathrm{A} 5$ transitions, the direct $\mathrm{NaCl} \rightarrow \beta-\mathrm{Sn}, \mathrm{NaCl} \rightarrow \mathrm{L} 10$ and $\mathrm{NaCl} \rightarrow \mathrm{CsCl}$ transitions were also investigated. The variations of the curves (volume versus applied pressure $P-\left(V_{p} / V_{0}\right)$ for $\mathrm{ScN}$ ) for the $\mathrm{NaCl} \rightarrow \mathrm{CsCl}$ transition are plotted in Fig. 4.

ISSN 2071-0194. Ukr. J. Phys. 2021. Vol. 66, No. 8 
During the structural transitions from, B1 $\rightarrow$ A5, $\mathrm{B} 1 \rightarrow \mathrm{L} 10$ and $\mathrm{B} 1 \rightarrow \mathrm{B} 2$, the reductions in the volume were found at around $14.25,16.33$, and $2.15 \%$, respectively. Our results regarding the reductions in volume from $\mathrm{B} 1$ phase to other structures for $\mathrm{ScN}$ are summarized in Table 3 together with other data from the literature.

The crystal density (called also mass density) $g$ is one of the simplest and most important material parameters. It is related to the atomic arrangement and the corresponding electron density map [26]. The mass density $\rho$ represents the ratio of the mass to the volume; it is usually expressed in $\mathrm{kg} / \mathrm{m}^{3}$ (or in $\left.\mathrm{g} / \mathrm{cm}^{3}\right)$. It is given as follows [38]:

$\rho=\frac{M Z}{N_{A} V}$.

In the NaCl-type structure, the unit cell volume $V$ was taken equal to $a^{3}$ ( $a$ is the lattice constant), while the number of molecules per unit cell was taken equal to 4 . Figure 5 indicates the crystal density behavior of the NaCl-type, CaSi-type, and $\beta$-Sn-type structures of the ScN crystal under pressure.

At the equilibrium, our obtained value $\left(4.242 \mathrm{~g} / \mathrm{cm}^{3}\right)$ of the mass density $\rho$ of the B1 phase underestimates the theoretical result $\left(4.25 \mathrm{~g} / \mathrm{cm}^{3}\right)$ reported in Ref. [39] by less than $0.20 \%$. As is well known, the mass density of wurtzite-cadmium sulfide (w-CdS) binary compound [24], copper nitride $\left(\mathrm{Cu}_{3} \mathrm{~N}\right)$ with cubic anti- $\mathrm{ReO}_{3}$ structure [40], wurtzite-zinc sulfide (B4-ZnS) [41], and cubic zinc-blende boron antimonide (BSb) [42] exhibit clear increments under compression. This is also the case for the NaCl-type, CaSi-type, and $\beta$-Sn-type structures of the $\mathrm{ScN}$ crystal under pressure, as seen in Fig. 5.

\subsection{Electronic properties}

We have calculated the electronic band structure of $\mathrm{ScN}$ for the new $\beta$-Sn-type (A5) phase using the FPLAPW method with the GGA approach. In Fig. 6, the electronic structure calculations for the A5 phase show that the $\mathrm{ScN}$ compound exhibits a large direct fundamental gap between the top of the valence bands (VB) and the bottom of the conduction band (CB). Our results predict the band gap energy for bulk $\mathrm{ScN}$ of about $E_{g}=1.975 \mathrm{eV}$. This value is slightly higher than the theoretical values 1.82 and $1.96 \mathrm{eV}$ of the NaCl-type phase obtained in [43] and [44], respectively.

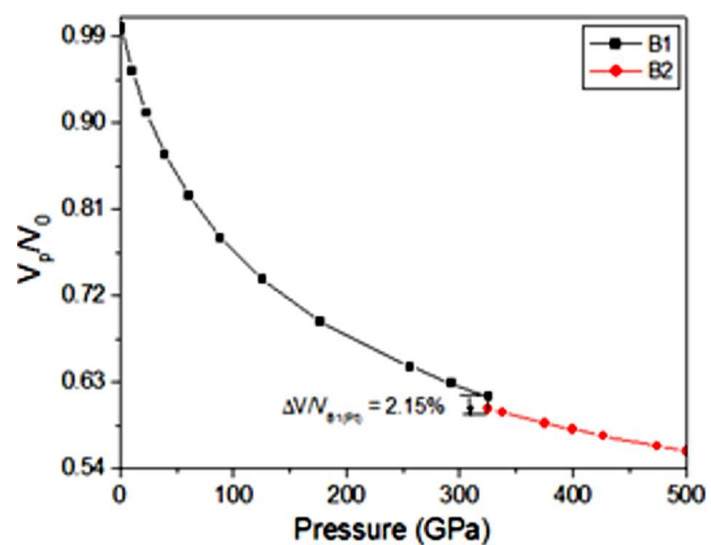

Fig. 4. $\left(V_{p} / V_{0}\right)$ versus pressure for the $\mathrm{B} 1 \rightarrow \mathrm{B} 2$ transition in $\mathrm{ScN}$ semiconducting compound

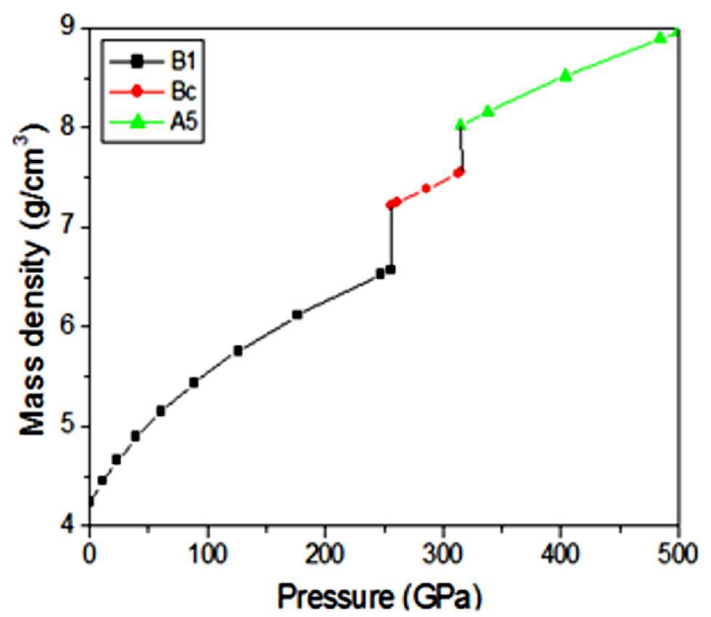

Fig. 5. Mass density $\rho$ versus pressure for the $\mathrm{NaCl}$ (B1), $\mathrm{CaSi}(\mathrm{Bc})$, and $\beta$-Sn (A5) phases of $\mathrm{ScN}$

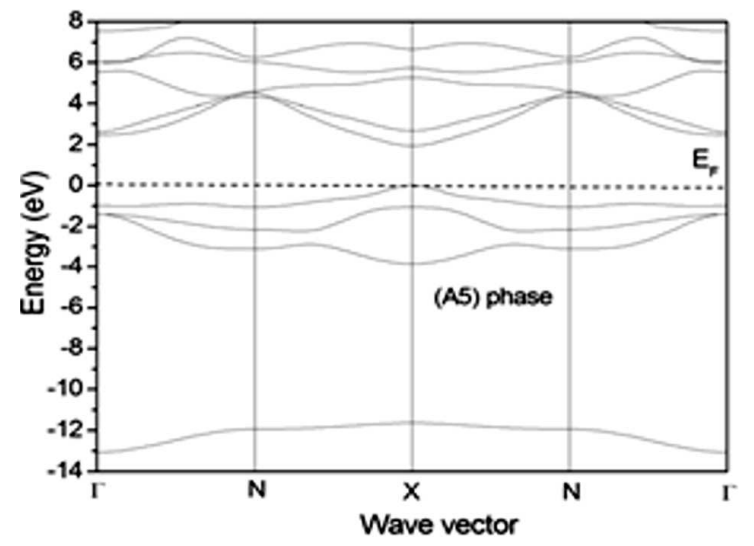

Fig. 6. Band structure of $\mathrm{ScN}$ in the $\beta$-Sn-type (A5) structure using the FP-LAPW method 


\section{Conclusion}

In summary, the structural parameters of $\mathrm{ScN}$ semiconducting compound in the NaCl-type, CsCltype, ZnS-type, wurtzite-type, CuAu-type, NiAstype, CaSi-type, and $\beta$-Sn-type phases have been investigated using the FP-LAPW approach, within the GGA. The ground state parameters were predicted and compared with other available experimental and theoretical data. The main results of the present work can be summarized as follows, We confirm that the B1 phase is the ground state for $\mathrm{ScN}$, with melting point predicted at around $2477.4 \mathrm{~K}$. At highpressures, we predict new phase transitions from B1 to $\beta$-Sn-type (A5) structure at $286.82 \mathrm{GPa}$ and from the CaSi-type BC phase to the $\beta$-Sn-type one (A5) at $315 \mathrm{GPa}$. Our results clearly indicate that there are the structural transitions from B1 to (BC, L10, and B2)-type configurations at 256.27 GPa, 302.08 GPa, and $325.97 \mathrm{GPa}$, respectively, for $\mathrm{ScN}$ confirming theoretical suggestions. The electronic structure calculation for A5 phase shows that the $\mathrm{ScN}$ exhibits a large direct band gap at $\mathrm{X}$ point near $1.975 \mathrm{eV}$.

1. 1. H. Berkok, A. Tebboune, M.N. Belkaid. Structural properties and new phase transitions of ScN using FP-LMTO method. Physica B 406, 3836 (2011).

2. B. Ul Haq, A. Afaq, G. Abdellatif, R. Ahmed, S. Naseem, R. Khenata. First principles study of scandium nitride and yttrium nitride alloy system: Prospective material for optoelectronics. Superlattice Microst. 85, 24 (2015).

3. B. Biswas, B. Saha. Development of semiconducting ScN. Phys. Rev. Materials. 3, 020301 (2019).

4. A. Maachou, B. Amrani, M. Driz. Structural and electronic properties of III-V scandium compounds. Physica B $\mathbf{3 8 8}$, 384 (2007).

5. S. Tahri, A. Qteish, I.I. Al-Qasir, N. Meskini. Vibrational and thermal properties of $\mathrm{ScN}$ and $\mathrm{YN}$ : Quasiharmonic approximation calculations and anharmonic effects. J. Phys. Condens. Matter. 24, 035401 (2012).

6. V. Adhikari, N.J. Szymanski, I. Khatri, D. Gall, S.V. Khare. First principles investigation into the phase stability and enhanced hardness of TiN-ScN and TiN-YN alloys. Thin Solid Films 688, 137284 (2019).

7. M.J. Winiarski, D. Kowalska. Structural, electronic, optical and magnetic properties of EuO and DyO compounds: Ab initio study. Mater. Res. Express 6, 095910 (2019).

8. A.T.A. Meenaatci, R. Rajeswarapalanichamy, K. Iyakutti. Investigation of structural stability and electronic properties of group III nitrides: A first principles study. Phase Transit. 86, 570 (2013).

9. H. Rekab-Djabri, R. Khatir, S. Louhibi-Fasla, I. Messaoudi, H. Achour. FPLMTO study of new phase changes in $\mathrm{CuX}(\mathrm{X}=\mathrm{Cl}, \mathrm{Br}, \mathrm{I})$ compounds under hydrostatic pressure. Comput. Condens. Matter. 10, 15 (2017).

10. L. Boudaoud, W. Adli, R. Mecheref, N. Sekkal, F. Tair, B. Amrani, S. Louhibi, A. Tebboune. Electronic properties of cubic ScGaAs and ScGaN ternaries and superlattices. Superlattice Microst. 47, 361 (2010).

11. P. Perdew, Y. Wang. Erratum: Accurate and simple analytic representation of the electron-gas correlation energy. Phys. Rev. B 45, 13244 (1992).

12. P. Blaha, K. Schwarz, G.K.H. Madsen, D. Kvasnicka, J. Luitz. WIEN2k: An Augmented Plane Wave Plus Local Orbitals Program for Calculating Crystal Properties. Edited by K. Schwarz (Vienna University of Technology, 2001).

13. P. Hohenberg, W. Kohn. In homogeneous electron gas. Phys. Rev. B 136, 864 (1964).

14. W. Kohn, L.J. Sham. Self-consistent equations including exchange and correlation effect. Phys. Rev. A 140, 1133 (1965).

15. J.P. Perdew, Y. Wang. Accurate and simple analytic representation of the electron-gas correlation energy. Phys. Rev. $B$ 45, 13244 (1992).

16. L.A. Palomino-Rojas, M. Lypez-Fuentes, G.H. Cocoletzi, G. Murrieta, Romeo de Coss, N. Takeuchi. Density functional study of the structural properties of silver halides: LDA vs GGA calculations. Solid State Sci. 10, 1228 (2008).

17. F.D. Murnaghan. The compressibility of media under extreme pressures. Proc. Natl. Acad. Sci. USA30, 5390 (1944).

18. A.R. Oganov, J.P. Brodholt, G.D. Price. Ab Initio Theory of Phase Transitions and Thermoelasticity of Minerals. Edited by C.M. Gramaccioli (E'otv'os University Press, Budapest, 2002).

19. R. Yagoub, A. Hadjfatah, S. Louhibi-Fasla, S. Daoud, S. Bahlouli, A. Haichour, C. Zegadi. J. Nano-Electron. Phys. 12 (5), 05009 (2020).

20. A. Tebboune, D. Rached, A. Benzair, N. Sekkal, A.H. Belbachir. Structural and electronic properties of ScSb, ScAs, ScP and ScN. Phys. Status Solidi B 243, 2788 (2006).

21. N. Takeuchi. First-principles calculations of the groundstate properties and stability of ScN. Phys. Rev. B 65, 045204 (2002).

22. D. Gall, I. Petrov, N. Hellgren, L. Hulman, J-E. Sundgren, J.E. Greene. Growth of poly- and single-crystal ScN on $\mathrm{MgO}(001)$ : Role of low-energy $\mathrm{N} 2+$ irradiation in determining texture, microstructure evolution, and mechanical properties. J. Appl. Phys. 84, 6034 (1998).

23. S. Daoud, N. Bioud, N. Lebga, L. Belagraa, R. Mezouar. Pressure effect on structural, elastic and electronic properties of (B3) BSb compoundIndian. J. Phys. 87, 355 (2013).

24. M. Güler, E. Güler. Elastic, mechanical and phonon behavior of wurtzite cadmium sulfide under Pressure. Crystals. 7, 164 (2017).

25. M. Benchehima, H. Abid, K. Benchikh. First-principles calculations of the structural and optoelectronic properties of 
$\mathrm{BSb}_{1-x} \mathrm{As}_{x}$ ternary alloys in zinc blende structure. Mater. Chem. Phys. 198, 214 (2017).

26. S. Adachi. Properties of Group-IV, III-V and II-VI Semiconductors (Wiley, 2005) [ISBN: 9780470090329].

27. V.P. Vasil'ev, J.-C. Gachon.Thermodynamic properties of III-V compounds. Inorg. Mater. 42, 1176 (2006).

28. M.E. Fine, L.D. Brown, H.L. Marcus. Elastic constants versus melting temperature in metals. Scr. Mater. 18, 951 (1984).

29. W. Feng, S. Cui, H. Hu, G. Zhang, Z. Lv, Z. Gong. Phase stability, electronic and elastic properties of ScN. Physica $B$ 405, 2599 (2010).

30. E. Ghafari, E. Witkoske, Y. Liu, C. Zhang, X. Jiang, A. Bukowski, B. Kucukgok, M. Lundstrom, I.T. Ferguson, N. Lu. Waste Energy Harvesting Using III-Nitrides Materials, in III-Nitride Materials, Devices and NanoStructures. Edited by Z.C. Feng, (World Scientific, 2017).

31. K.A. Gschneidner, jr. Inorganic Compounds. In: Scandium, Its Occurrence, Chemistry, Physics, Metallurgy, Biology, and Technology. Edited by C.T. Horovitz (Academic press, 1975) [ISBN: 978-0-12-355850-3].

32. N. Bouarissa. Pressure dependence of optoelectronic properties of $\mathrm{GaN}$ in the zinc-blende structure. Mater. Chem. Phys. 73, 51 (2002).

33. P. Bhardwaj, S. Singh. High pressure phase transition and elastic properties of covalent heavy rare-earth antimonides. J. Mol. Model. 17, 3057 (2011).

34. D. Olego, M. Cardona. Pressure dependence of Raman phonons of Ge and 3C-SiC. Phys. Rev. B 25, 1151 (1982).

35. M. Aynyas, S.P. Sanyal, P.K. Jha. Structural phase transition and elastic properties of thorium pnictides at high pressure. Phys. Status Solidi B 229, 1459 (2002).

36. P. Bhardwaj, S. Singh, N.K. Gaur. Structural, elastic and thermophysical properties of divalent metal oxides with $\mathrm{NaCl}$ structure. Mat. Res. Bull. 44, 1366 (2009).

37. P. Bhardwaj, R. Bhardwaj, S. Singh. Computational study of ScN. Procedia Comput. Sci. 57, 57 (2015).

38. R.E. Newnham. Properties of Materials: Anisotropy, Symmetry, Structure (Oxford University Press, 2005) [ISBN: 0-19-852075-1].

39. D. Holec, M. Friak, J. Neugebauer, P.H. Mayrhofer. Trends in the elastic response of binary early transition metal nitrides. Phys. Rev. B 85, 064101 (2012).

40. S. Daoud. Comment on the effect of pressure on the physical properties of $\mathrm{Cu}_{3}$ N. Phys. Scr. 91, 057001 (2016).
41. M. Güler, E. Güler. Theoretical analysis of elastic, mechanical and phonon properties of wurtzite zinc sulfide under pressure. Crystals. 7, 161 (2017).

42. S. Daoud. Structural and piezoelectric properties of BSb under high pressure: a DFT study. J. Nano-Electron. Phys. 11 (5), 05004 (2019).

43. R. Mohammad, S. Katircioglu. A comparative study for structural and electronic properties of single-crystal ScN. Condens. Matter Phys. 14, 23701 (2011).

44. J. Liu, X-B. Li, H. Zhang, W-J. Yin, H-B. Zhang, P. Peng, L-M. Liu. Electronic structures and optical properties of two-dimensional ScN and YN nanosheets. J. Appl. Phys. 115, 093504 (2014).

Received 13.11.20

Р. Ягуб, Г. Реккаб Дябрі, С. Дауд,

Н. Белуфа, М. Беларбі, А. Хайчур,

К. Зегадi, С. Лухібі Фаслі

ДОСЛІДЖЕННЯ ФАЗ

ScN ПРИ ВИСОКОМУ ТИСКУ

З ПЕРШИХ ПРИНЦИПІВ

Представлено результати повноенергетичних розрахунків з перших принципів структурних властивостей напівпровідника нітриду скандію (ScN) в структурах типу $\mathrm{NaCl}$ (B1), $\mathrm{CsCl}$ (B2), сфалериту (В3), вюрциту (B4), NiAs (B81), $\mathrm{CaSi}(\mathrm{Bc}), \beta-\mathrm{Sn}$ (A5), і CuAu (L10). Розрахунки виконано багатоелектронним повнопотенціальним методом лінеаризованих приєднаних плоских хвиль, заснованим на теоріі функціонала густини в наближенні узагальненого градієнта для функціонала обмінної кореляційної енергї. Передбачено новий фазовий перехід із найбільш стабільної кубічного типу $\mathrm{NaCl}$ структури (B1) в структуру типу $\beta$-Sn (A5) при тиску 286,82 ГПа з величиною прямозонної щілини близько 1,975 еВ. Ми показали, що $\mathrm{ScN}$ перетвориться з орторомбічного типу CaS структури (Bc) в А5 при 315 ГПа. Відповідно до відомих $a b$ initio розрахунків, ми знайшли, що В1 фаза переходить у Bc, L10 та В2 структури при 256,27 ГПа, 302,08 ГПа і 325,97 ГПа, відповідно. Електронна структура фази $\mathrm{A} 5$ показує, що $\mathrm{ScN}$ має прямозонну щілину в $\mathrm{X}$ точці з $E_{g}$ близько $1,975 \mathrm{eB}$.

Ключов $i$ слова: повнопотенціальний метод лінеаризованих приєднаних плоских хвиль, нітрид скандію, фазовий перехід, наближення узагальненого градієнта, електронна структура. 